\title{
MICROMECHANISMS OF LOAD HISTORY EFFECTS IN FATIGUE- DRIVEN DELAMINATION GROWTH
}

\author{
$\underline{\text { Simon M. Jensen }}^{1^{*}}$, Brian L.V. Bak $^{1}$, Esben Lindgaard ${ }^{1}$, Jordi Renart ${ }^{2}$ \\ ${ }^{1}$ The CraCS research group, Aalborg University, Fibigerstræde 16, 9220 Aalborg East, Denmark \\ ${ }^{2}$ AMADE, Polytechnic School, University of Girona, Campus Montilivi s/n, Girona 17071, Spain \\ *smj@mp.aau.dk
}

The load history has an important influence on fatigue-driven delamination growth in laminated FRP composites - particularly when frequent changes in load amplitude occur. Recent experimental characterisation techniques facilitate to identify several peculiar delamination growth phenomena due to variable amplitude load histories [1-3] yet the underlying damage processes are unidentified. Fiber bridging is a common and significant mechanism in the process zone of a delamination crack, which is known to enhance the fracture toughness and reduce the crack growth rate in fatigue. However, the dependence of the bridging mechanisms on the load history are unknown, which may be the main responsible for the load history effects.

A model of the bridging fibres and their influence on the crack tip driving forces as a function of the load history has been developed. The model includes a well-defined macroscopic crack tip and a discrete representation of bridging fibres. The propagation of the macroscopic crack tip is described by LEFM, while a novel micromechanical model describes the individual bridging fibres. The micromechanical model is a geometrical non-linear FE model using a 2D co-rotational frame element formulation implemented in MATLAB, see Fig. 1.

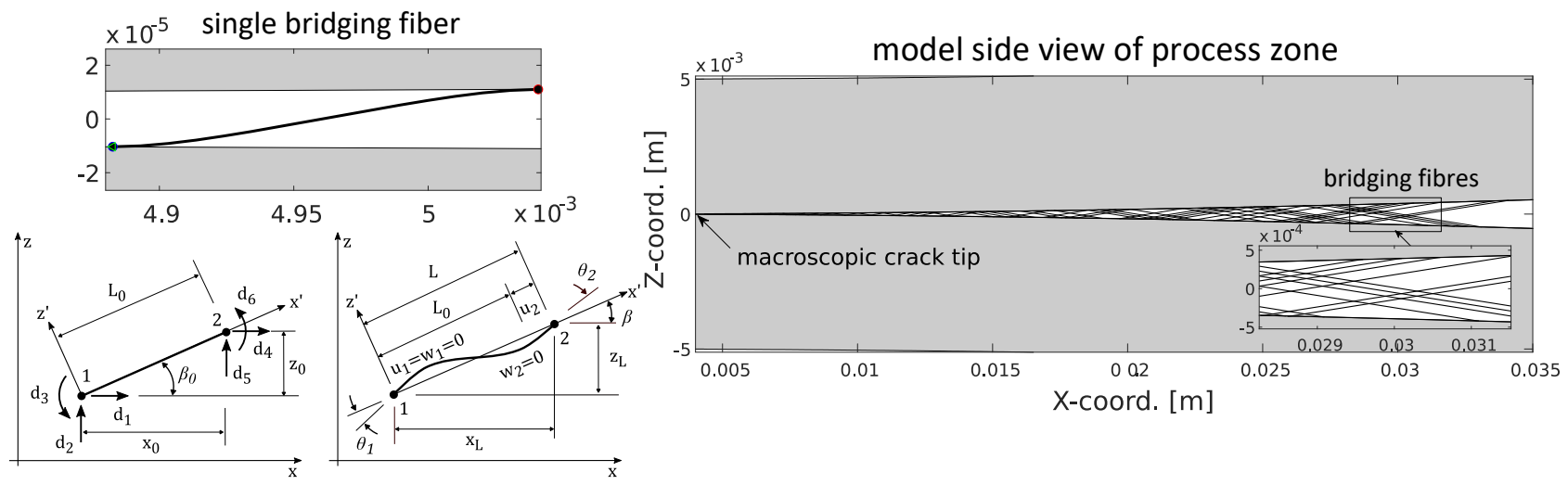

Figure 1. Co-rotational frame elements model each individual bridging fiber. FE models of the bridging fibres are embedded in a structural DCB model with a macroscopic crack tip in a LEFM framework.

A qualitative analysis of load history effects on the fatigue crack growth rate is presented in comparison to experimental results and observations. The process zone proves to be load history dependent, which has a significant effect on fatigue-driven delamination growth. This questions the validity of the common practice in state-of-the-art crack growth rate models.

\section{References}

[1] S.M. Jensen, B.L.V. Bak, J.J. Bender, E. Lindgaard (2021) Transition-behaviours in fatigue-driven delamination of GFRP laminates following step changes in block amplitude loading, International Journal of Fatigue, 144, doi: https://doi.org/10.1016/j.ijfatigue.2020.106045.

[2] B.L.V. Bak and E. Lindgaard (2020) A method for automated digital image-based tracking of delamination fronts in translucent glass fibre-laminated composite materials, Strain, 56, doi: https://doi.org/10.1111/str.12345

[3] S.M. Jensen, B.L.V. Bak, J.J. Bender, L. Carreras, E. Lindgaard, Transient delamination growth in FRP laminates with fiber bridging under variable amplitude loading in G-control, (In preparation) 